\title{
An Accurate Carbon Accounting Model Based on the Micro-level Process Principles for the Lean Carbon Management in the Blast Furnace Ironmaking
}

\section{Shujun Yu}

Wuhan University of Science and Technology

\section{Fangjia Lin}

Wuhan University of Science and Technology

Gang Zhao ( $\square$ jasonzhao@wust.edu.cn )

Wuhan University of Science and Technology https://orcid.org/0000-0002-1430-4959

\section{Zequan Zhang}

Wuhan University of Science and Technology

\section{Hua Zhang}

Wuhan University of Science and Technology

\section{Research}

Keywords: carbon management, carbon accounting, carbon emission, S-system, power law approximation, Michaelis-Menten law

Posted Date: May 18th, 2021

DOI: https://doi.org/10.21203/rs.3.rs-435039/v1

License: (c) (i) This work is licensed under a Creative Commons Attribution 4.0 International License.

Read Full License 


\title{
An accurate carbon accounting model based on the micro-level process principles
} for the lean carbon management in the blast furnace ironmaking

\author{
Shujun $\mathrm{Yu}^{1}$, Fangjia Lin ${ }^{1}$, Gang Zhao ${ }^{2, *}$, Zequan Zhang ${ }^{3}$, Hua Zhang ${ }^{4}$
}

${ }^{1}$ Evergande School of Management, Wuhan University of Science and Technology, Wuhan, Hubei 430081, China

${ }^{2}$ Hubei Key Laboratory of Mechanical Transmission and Manufacturing Engineering, Wuhan University of Science and Technology, Wuhan, Hubei 430081, China

${ }^{3}$ Key Laboratory of Metallurgical Equipment and Control Technology of Ministry of Education, Wuhan University of Science and Technology, Wuhan, Hubei 430081, China

${ }^{4}$ Academy of Green Manufacturing Engineering, Wuhan University of Science and Technology, Wuhan, Hubei 430081, China

*Corresponding Author: Gang Zhao_～Email: jasonzhao@wust.edu.cn

\begin{abstract}
:
Background: The carbon accounting plays a critical role in the lean carbon management and the policy formulation for industrial entities. The carbon accounting method based on emission factors offered by IPCC usually leads significant errors on the micro-level of the enterprise. For achieving a bottom-up lean carbon management with higher accounting accuracy, a micro-carbon accounting model based on the micro-level process principles is established on a S-system of dynamics with using the approximation method of power law and Michaelis-Menten law. It is used to predict the amounts of various resources and output products at the process nodes under predetermined simulation conditions.

Results: In the case study on a blast furnace ironmaking system, it succeeds in accurately predicting the amount of products including carbon emissions depending on the massive variables of materials and fuels. Further study on the residual analysis shows that mean errors of the $\mathrm{CO}_{2}$ and $\mathrm{CO}$ emissions are respectively $5.23 \%$ and $6.77 \%$ while using the micro-carbon accounting model.

Conclusions: This method better addresses the challenge of severely overestimation on carbon emissions in the carbon accounting of the ironmaking industry. It offers a prospective and accurate carbon accounting model further for formulating more targeted policies of the lean carbon management at a micro-level of an enterprise.
\end{abstract}

Keywords: carbon management, carbon accounting, carbon emission, S-system, power law approximation, Michaelis-Menten law

\section{Background}

During the 14th Five-Year Plan, China will continue to establish eight categories of highemission industries, covering power, steel, petroleum, chemical, building materials, nonferrous metals, paper-making, and aviation. With more than 7,000 entities producing an annual emission of 4 - 5 billion tons, it will be the world's largest carbon emissions trading market with a possible transaction amount of 16 billion US dollars (National Development and Reform Commission of P. R. China., 2016). As the most important players in the carbon emission trading market, steel companies need to build the lean carbon management system to improve the capabilities of 
accumulating and managing the carbon assets. It is the key thrust to improve the low-carbon competitiveness of the steel industry, and further enhance the vitality of the national carbon market.

Marland et al. proposed for the first time that carbon emission reductions should be used as carbon emission rights, making them as the carbon assets with trading values (Marland $\mathrm{G}$, et al. 2001). Later, carbon assets such as the low-carbon technologies with the value of carbon emission reduction (Han Liyan, et al. 2015), the carbon sinks with the value of carbon balance and carbon investment (Pany, et al. 2011), etc. were gradually studied in the field of management research. Under the mechanism of carbon trading market, a carbon management system was regulated on the basis of the carbon verification, the carbon decision-making, and the carbon disclosure (YI Lan, et al. 2016). Among them, the carbon decision-making is the core of the top-level design of carbon management. Scholars in China and abroad have fully studied the impacts of carbon trading mechanism (ZHANG Junrong, et al. 2016), carbon allowance (MA Qiuzhuo, et al. 2014), carbon supply chain (Butner K., et al. 2008), carbon price, carbon finance (WANG Sufeng, et al. 2016), etc. on the carbon decision-making. They established the carbon decision model to describe the management activities of the carbon assets for those enterprises in the carbon trading market under the constraints of external conditions. However, carbon assets are hardly directly controllable. Only after discovering the quantitative relationship between the carbon assets and the enterprise internal resources, the process equipment, and the production scheduling, the bottom-up digital decisionmaking and the lean carbon management could be realized for the steel enterprises.

Actually, the carbon accounting provides a data basis for digital decision-making and lean carbon management. According to the acts of Directive 2004/156/EC and Directive 2007/589/EC issued by the European Commission in 2004 and 2007, the current international carbon accounting mainly depends on 2 types of methods: One is Continuous Emission Monitoring (CEM), using sensors to continuously monitor the $\mathrm{CO}_{2}$ emissions from carbon sources; the other type uses the $\mathrm{CO}_{2}$ emission factors and oxidation factors provided by the United Nations' Intergovernmental Panel on Climate Change (IPCC), and uses the consumption data of raw fuels and electricity power to calculate the direct and indirect carbon emissions (T. Spengler, et al. 1998). Due to the high cost of long-term deployment of the CEM system (J. Davis, et al. 2007), the IPCC's carbon accounting method based on emission factors (Jan Peter Andersen, et al. 2001) is usually used in engineering practices for carbon accounting in China and abroad. The carbon emission is estimated by the product of emission factors, oxidation factors and net calorific values of fuels. The emission factor is essentially a series of pattern recognition parameters relevant to various fuels. The emission factor based method is actually a statistic model depending on the historical fuel data rather than a mechanism model based on the process structure. It simplifies the carbon emission process of industrial entities into a linear IO system. It only considers the carbon emissions generated by fuel consumptions, and completely ignores the impacts of the entities' internal structure and their complex production processes on the real carbon emissions.

All these lead to large errors in the carbon accounting based on emission factors. The study conducted by Tsinghua University shows that the calculation error of carbon emissions with the emission factor based method reaches up 27\% to 35\% (Ana-Maria Iosif, et al. 2008). Similarly, the project of Los Angeles Reclaim in the United States even claims a calculation error of up to $50 \%$ (C. Rynikiewicz, 2008). The study in the field of steel industry shows that carbon emission calculation tool for the steel industry jointly developed by the World Resources Institute (WRI) and the World Business Council for Sustainable Development (WBCSD) (Mohan Yellishetty, et al. 
2011), as same as the carbon emission factors recommended by the World Iron and Steel Association (WSA) (Mohan Yellishetty, et al. 2011; Karen R. Polenske, et al. 2002), are not suitable for the carbon accounting of Chinese steel industry. The carbon emissions in Chinese steel industry are generally overestimated. The reason lies on the differences in the product categories (especially the ratio of iron to steel), The energy categories, the level of technology and equipment, the process conditions (especially the quality of raw materials and fuels) between Chinese and foreign steel industry. In order to correct the carbon accounting errors, the academic community is currently focusing on the correction of emission factors (Academician LU Zhongwu, et al. 2000; 2010) rather than proposing a principle model of carbon emissions based on the metallurgical processes. (Qiangfeng Li, et al. [20]) finds that the emission factors of iron ore, pig iron, crude steel, rolled steel, and industrial coke in Chinese steel industry are higher than those in developed countries, and proposes a method of shared responsibility principle (SRP) to calculate carbon emissions for China. A more objective assessment of carbon emissions makes international carbon credits more fair and reasonable. The corrected emission factor is feasible when calculating the average carbon emissions in an industry or a region. However, it is difficult to estimate the real emissions of a company, the impact of company's decision-making and process improvement on carbon emissions. Therefore, the emission factor greatly limits the development of the digital model of lean carbon management for a steel company, while being used for the carbon accounting at an enterprise level.

For more accurate estimation on the carbon emission independing on the emission factor, many scholars attempt to propose and develop new approaches to establish a bottom-up model. (Scott Kelly et al. [16]) uses CiteSpace software and knowledge mapping methods to conduct quantitative analysis of literatures, and determines 5 general measurement methods of carbon emissions: Environmental Expansion Input-Output Analysis (EE-IOA), Index Decomposition Analysis (IDA), Econometric Analysis, Carbon Emission Control Efficiency Evaluation and relevant simulation analysis. The direct analysis and comparison of these methods help scholars quickly identify and compare different methods to solve specific engineering issues. (Yuanbo Geng et al. [18]) uses a Raw Material Carbonate Method (RMCM) to calculate the power consumption of the new type of suspension preheater and precalciner kiln and the process-related power consumption. Through analyzing the sample composition of the cement production line, they conclude that RMCM method is more accurate and simple comparing with the emission factor method provided by IPCC. (Qi Lu [21]) proposed a method based on Embedded Carbon Energy (ECE) of products/components/parts for carbon emissions calculation. This method provides a new idea for the calculation of carbon emissions in the major life cycle of products. It accurately calculates the carbon emissions depending on the product rather than the system boundary for the low-carbon design. Libao Yin [22] establishes a $\mathrm{CO}_{2}$ emission calculation model suitable for most coal-fired boilers. The model uses the industrial analysis on the fuel consumption/coal consumption as the input data and outcome the carbon dioxide emission data. The BP neural network is used to determine the carbon content of coal. Its error is much smaller than that of the emission factor method and the capacity standard method. (Bofeng Cai et al. [24]) develops a reconstructed scale model through combining the emission source data with the existing official statistical data. With this model, they build a grid with $1 \mathrm{~km}$ resolution for mapping the visual carbon emission data in Beijing-Tianjin-Hebei region of China in 2012. For the study on the steel industry, many achievements also are contributed by the scholars around the world. (Hannu Suopajarvi et al. [25]) uses a sample of carbon emission data report from a steel plant and improves the blast furnace process to reduce the excessive carbon 
emissions in blast furnace ironmaking. (Chang Houn Rhee et al. [27]) uses the chemical experiment method to carry out the quality inspection on blast furnace gas and concluded that carbon emission of the blast furnace is related to the complexity of the materials in the blast furnace. (Qi Zhang et al. [26]) uses the Material Flow Analysis (MFA) method in the industrial ecology in order to simulate and systematically evaluate the carbon flow of materials in the steel industry, relevant to the space and the time. Through integrating the resources, pathways, and intermediate processes, the carbon input and output in system boundaries of steel plants is analyzed to discover the laws of the systemic behaviors.

The steel industry consists of a large scale of enterprises, numerous production departments, and possesses a complex structure. Literature reviews have shown that lean and controllable carbon management for complex steel industrial systems faces some theoretical challenges listed as the following.

(1) The statistics of carbon accounting is difficult with a long statistic cycle (Gang Zhao, et al. 2018; Zhang Haiou, et al. 2020). The computing accuracy of carbon emissions is seriously insufficient. It is difficult to guarantee the accuracy, completeness and timeliness of the data of carbon emissions and carbon assets. High-quality carbon accounting data is the technical guarantee for the objective and fairness of the rules inthe carbon trading market.

(2) The validation of the theoretical model of carbon management is insufficient (Zhang Yalian, et al. 2013). Currently, Chinese and foreign studies usually pay more attention to the toplevel principles of the carbon trading (Wang Yanglei, et al. 2015), the carbon allowance (Wang Wenju, et al. 2019), the carbon finance (Wang Wenjun, et al. 2016), and the carbon decision (ZHAO Liming, et al. 2016) that is performed between the market, the government and the enterprises at a macro-level. However, the accuracy of carbon accounting at an enterprise level is insufficient since the fundamental principles and the key methods of the micro-carbon management deserve further study at an enterprise level (Gang Zhao, et al. 2015; 2019).

In summary, for achieving a lean carbon management in the steel industry, the accuracy and effectiveness of carbon accounting data need to be improved and a bottom-up lean carbon management method need to be proposed. This paper analyzes the ironmaking process flow of the blast furnace (BF) and then establishes a S-system dynamic model for predicting the carbon emissions in ironmaking, using the method of powerlaw approximation. It is used to predict the amounts of various resources and output productsat the process nodes under predetermined simulation conditions. Therefore, it is also used to accurately predictand lean manage the carbon emissions as the ironmaking process variables change, which offer a new mathematic model for accurately accounting the carbon emissions at a micro-level and further implementing the lean carbon management in an ironmaking enterprise. 


\section{A carbon accounting model based on the micro-level process principles}

\subsection{A S-system based dynamic formula expressing the carbon emission processes}

In the complex industrial system, the carbon emission processes usually exist with complex chemical reactions, which need to be formulated by the relationship between the concentrations of various products and their productionrate. Therefore, the production rate equation is expressed as Eq. (1) (Nestor V. Torres, 2010).

$$
v(X)=-k X
$$

In which, $k$ is the production rate constant (positive value), $X$ represents the reactants, and $v(X)$ represents the change amount of the reactant per minute, and the negative sign in the formula represents that reactant is continuously consumed. It can also be written in a derivative form, as shown in Eq. (2).

$$
\frac{d X}{d t}=\dot{X}=-k X
$$

Consider a simple irreversible reaction process $A \rightarrow B+C$, and $X$ represents the amount of substance $\mathrm{A}$ at the time $t$. Depending on the reaction principles, it is almost impossible to predict when a given substrate molecule A will transform into molecule B and C. However, if there are very many A molecules, the transformation processes of any given molecules can be regarded as a probabilistic process according to the statistical thermodynamics. The value $x$ decreases with the time elapsing just because the substance $A$ is not supplemented. The probability of the falling from $x$ to $x-1$ within an extremely short time interval $\Delta t$ is clearly defined as,

$$
P(x, t \rightarrow x-1, t+\Delta t)=k \cdot x \cdot \Delta t
$$

In which, if the selected $\Delta t$ is small enough, the value of $P$ will not drop while $x$ changes to $x-2, x-3, \cdots$.If $P_{x}(t)$ represents the probability that there are $x$ molecules at time $t$, then the probability that there are $x$ molecules at the timet $+\Delta t$ is expressed as

$$
P_{x}(t+\Delta t)=k \cdot(x+1) \cdot \Delta t \cdot P_{x+1}(t)+(1-k \cdot x \cdot \Delta t) \cdot P_{x}(t)
$$

On the right side of this formula, the first term represents the probability of the change from $x+1$ to $x$ molecules, and the second term represents the probability of stopping the next step from $x$ to $x-1$. When $\Delta t \rightarrow 0$, Eq. (4) becomes a set of differential equations. Each of them describes a given number of $X$ molecules' dynamics in the system. Via solving these equations, the expectation value of (the sample mean) reactant molecules at any time $\bar{x}$ is obtained as the following result.

$$
\bar{x}=x_{0} \cdot \exp (-k t)
$$

In which, $x_{0}$ is the amount of the initial reactant including all carbonaceous materials. This equation is the solution to the differential equation Eq. (2), which can be used to describe the microscopic dynamic process of the carbon emission.

\subsection{The approximation method of power law and Michaelis-Menten law}

The power law formula is equivalent to a linearization in the logarithmic coordinates. It is constructed on Taylor's theorem, which ensures that the differential function can be linearized correctly near the operating point. According to Taylor's theorem, $v(x)$ can be approximated by apolynomial ofdegree $n$ at the node $p$ 


$$
\begin{aligned}
v(x) & \approx v(p)+v^{\prime}(p)(x-p)+\frac{1}{2 !} v^{\prime}{ }^{\prime}(p)(x-p)^{2}+\frac{1}{3 !} v^{\prime} \prime^{\prime}(p)(x-p)^{3} \\
& +\cdots+\frac{1}{n !} v^{(n)}(p)(x-p)^{n}
\end{aligned}
$$

If all derivatives of $v$ exist, $n$ can tend to infinity. The Taylor's polynomial will be the exact expression of $v$.That is, while $n=1$, the corresponding linear expression formula is,

$$
v(x) \approx v(p)+v^{\prime}(p)(x-p)
$$

In order to explain the linearization process in detail, a simple form of Michaelis-Menten velocity law is taken into account.

$$
v=v(X)=\frac{v_{\max }}{K_{m}+S}
$$

The following formula is obtained by using logarithmic variables $w$ and $Y$.

$$
w=w(Y)=\ln \frac{v_{\max } \exp (Y)}{K_{m}+\exp (Y)}
$$

Via taking the derivative of $w$ with respect to $Y$, the slope rate of the velocity in the logarithmic space is obtained, as well as the slope rate of the expectation approximate function. That is, the derivative of $w$ is,

$$
\begin{aligned}
\frac{d w}{d y} & =\frac{K_{m}+\exp (Y)}{v_{\max } \exp (Y)} \frac{v_{\max } \exp (Y) \cdot\left[K_{m}+\exp (Y)-v_{\max } \cdot \exp (Y) \cdot \exp (Y)\right]}{\left[K_{m}+\exp (Y)\right]^{2}} \\
& =\frac{K_{m}}{K_{m}+\exp (Y)}
\end{aligned}
$$

Hence, in the logarithmic coordinates, the linear function of the Michaelis-Menten velocity law at the operating node $Y_{0}$ is,

$$
\begin{aligned}
w & \approx w\left(Y_{0}\right)+\frac{K_{m}}{K_{m}+\exp (Y)} \cdot\left(Y-Y_{0}\right) \\
& =\left[w\left(Y_{0}\right)-\frac{K_{m}}{K_{m}+\exp \left(Y_{0}\right)} \cdot Y_{0}\right]+\frac{K_{m}}{K_{m}+\exp \left(Y_{0}\right)} \cdot Y \\
& =\ln (\alpha)+g \cdot Y
\end{aligned}
$$

The terms in brackets depend on the operating node $Y_{0}$ rather than the variable $Y$. They are constant and all included in $\ln (\alpha)$. Similarly, $\mathrm{g}$ is also constant though depending on the operating nodes. In order to transform to the Cartesian coordinates, both sides of Eq. (11) are exponentiated simply as the following.

$$
v \approx \alpha \cdot X^{g}
$$

Therefore, the original velocity law can be approximated by a power law function with real exponents and positive multiples. In this equation, the exponent is called the dynamic progression, and the multiple is called the velocity constant. Above derivation shows that the dynamic progression is the derivative of the logarithmic function $v$ to the logarithmic variable $X$. Therefore, the dynamic progressionis directly calculated by the following Eq. (13).

$$
g=\frac{d w}{d Y}=\frac{d \ln v}{d \ln X}=\frac{d v}{d X} \cdot \frac{X}{V}
$$

Once the dynamic progression is calculated, the velocity constant then is obtained

$$
\alpha=v\left(X_{0}\right) \cdot\left(X_{0}\right)^{-g}
$$


The above equation is true while the function and its approximation are equal at the operating node $X_{0}$. The dynamic progression $g$ of the approximate equation according to the MichaelisMenten velocity law decreases from 1 to 0 . Obviously, when $X_{0}=K_{m}$, the dynamic progression $g=$ 0.5 . Although the values of the dynamic progressions and velocity constants vary with the selected operating nodes, the structure of the approximate equation is always same with the power law function like the type of $\alpha \cdot X^{g}$.

In order to calculate the approximate value of the velocity depending on the multivariable power $V\left(X_{1}, X_{2}, X_{3}, \mathrm{~L}, X_{n}\right)$, an operating node $P$ with n coordinate values $P 1, P 2, P 3, \ldots, P n$ is selected once more, and the similar steps of linearization in the $n+1$ logarithmic space are performed to obtain the following result. The product of the power law function is approximately expressed as $V$.

$$
V=\alpha \cdot X_{1}^{g_{1}} X_{2}^{g_{2}} X_{3}^{g_{3}} \mathrm{~L} X_{n}^{g_{n}}
$$

Each dynamic progression $g_{i}$ is calculated by the partial differentiation of $V$ to $X_{i}$ as the following Eq. (16). And the corresponding velocity constant is obtained by the following Eq. (17).

$$
\begin{aligned}
& g_{i}=\frac{\partial V}{\partial X_{i}} \cdot \frac{X_{i}}{V} \\
& \alpha=V\left(p_{1}, p_{2}, \mathrm{~L}, p_{n}\right) p_{1}^{-g_{1}} p_{2}^{-g_{2}} \mathrm{~L} p_{n}^{-g_{n}}
\end{aligned}
$$

All reactants of variables at the operating nodes are included in the expression formulas of power law so that the reaction velocity and the concentration of products are estimated accurately. This method is adequate and effective for accurately estimating the concentration, mass, and their change velocity of carbon emissions. 


\section{A micro-carbon accounting model for the blast furnace ironmaking system}

\subsection{Carbon emission principles of internal reactions in the blast furnace}

The blast furnace is a vertical reaction vessel, which is divided into 3 zones depending on the temperature field of each zone. The upper part is named the preheating zone (PZ, temperature less than $\left.950^{\circ} \mathrm{C}\right)$. The middle part is the thermal reservation zone or indirect reduction zone (RZ, the temperature is approximately $950^{\circ} \mathrm{C}$ ), and the lower part is the high temperature zone (EZ, the temperature is greater than $950^{\circ} \mathrm{C}$ ). The substance flow diagram is established as shown in Fig. 1 according to the ironmaking process of the blast furnace.

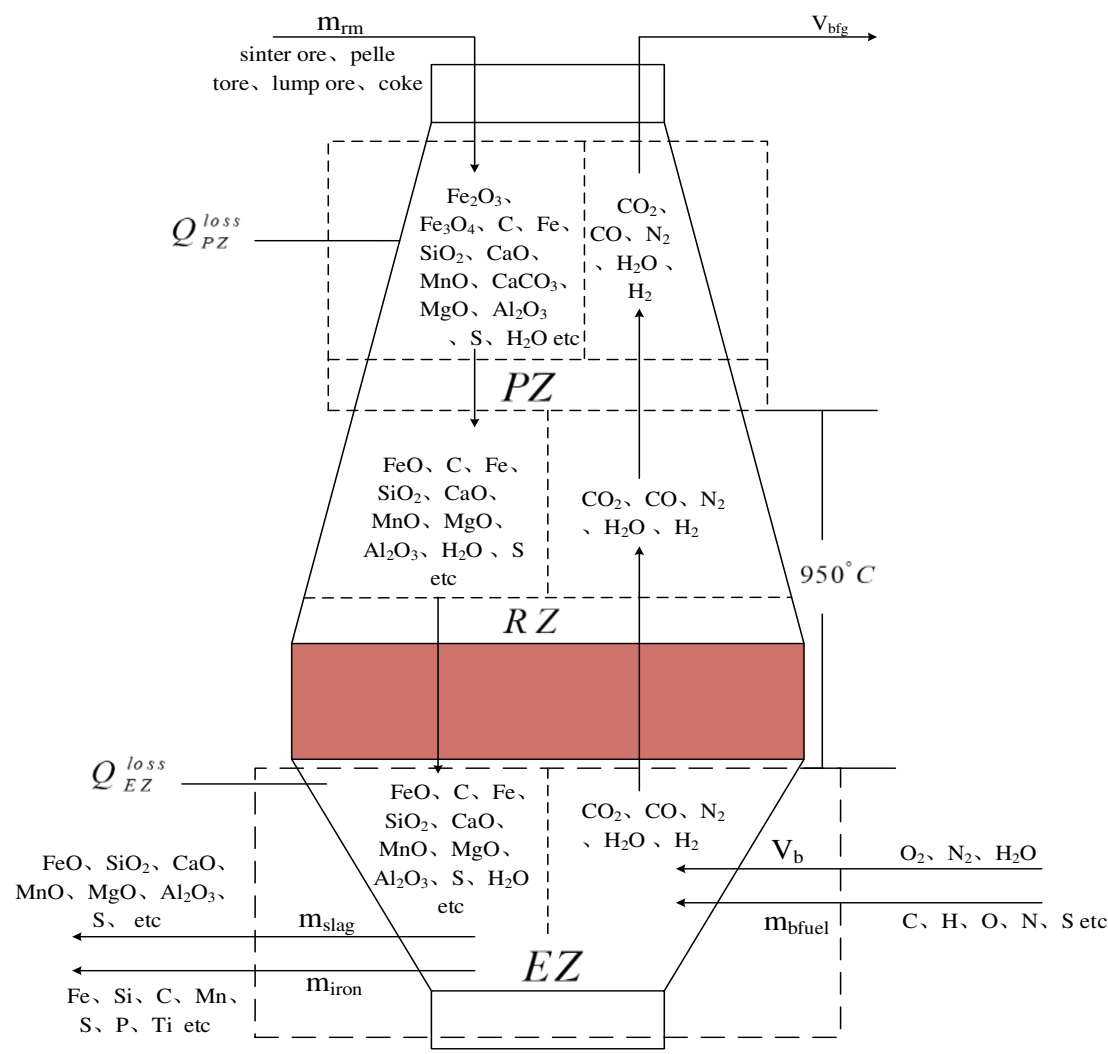

Fig. 1 The substance flows inside the blast furnace

The ironmaking process in the blast furnace is complex and consists of many chemical reactions in 3 phases of solid, liquid and gas. As the chart shown in Fig.2, the major inputs of the BF ironmaking system are the sinter, pellet, lump ore, coke, coal powder, and blast air. The outputs mainly are the slag, molten iron, dust, $\mathrm{BF}$ gas including $\mathrm{CO}_{2}$, etc. The solid and dashed arrows in the figure represent the state of each substance in each process. The raw materials enter into the BF and then gradually transform from solid phase to liquid phase and eventually discharge out of the furnace with $\mathrm{BF}$ gas, including the carbon emission of $\mathrm{CO}_{2}$. 


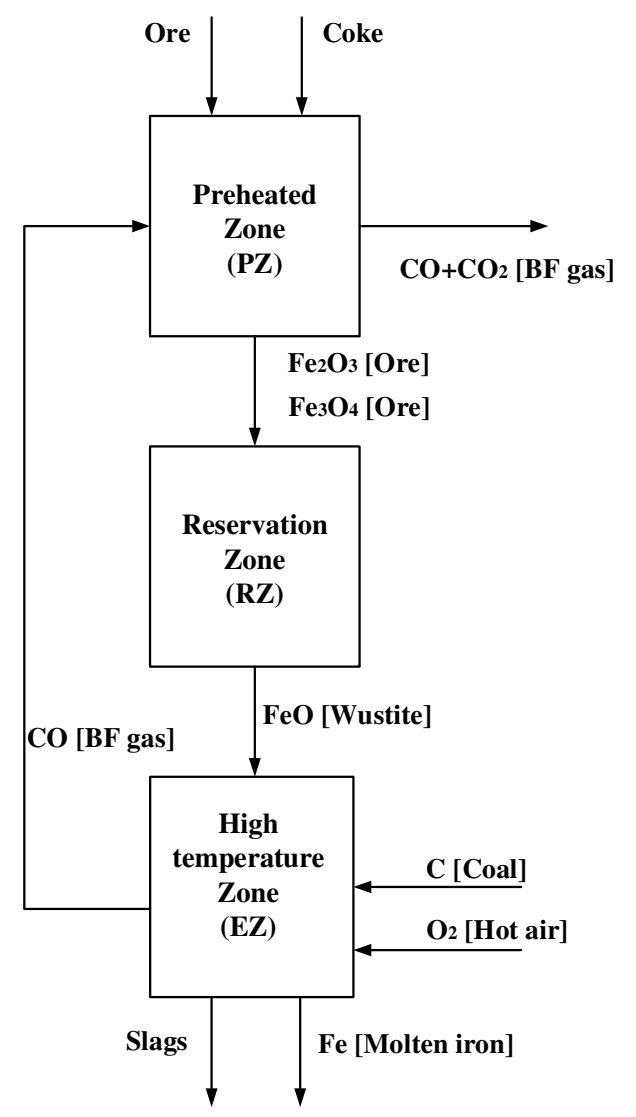

Fig. 2 The systemic dynamic model of the blast furnace ironmaking system

The carbon accounting model for blast furnace ironmaking is proposed depending on the systemic dynamic model with the corresponding differential equations and the stoichiometric matrices. Therefore, all chemical equations need to be listed to indicate the reactions occurring inside the blast furnace. Since the process of blast furnace ironmaking is complex and dynamic, some hypothesizes as the following are assumed during a processing cycle for the dynamic modeling.

(1) All ore is heated and softened in the preheating zone and subsequently enters the thermal reservation zone of the blast furnace.

(2) The combustion of the pulverized coal produces the reducing gas. All those reactions occur in the high temperature zone of the blast furnace.

(3) All pulverized coal is fully combusted, that is, with the combustion efficiency $100 \%$.

\subsection{The computation of BF carbon emissions using the micro-carbon accounting model}

As mentioned above, via establishing the micro-carbon accounting model based on the systemic dynamics with respect to the independent variables $X_{i}$ and the dependent variables $X_{j}$, a more accurate prediction on carbon emissions is proposed for the blast furnace ironmaking. The micro-carbon accounting model is obviously different from the prediction based on the historical statistics. Depending on the systemic dynamic model of the blast furnace ironmaking system 
established in Fig.2, all variables are identified as listed in Table 1. The independent variables $X_{i}(i=1,2, \cdots, 13)$ represents the original input materials of the BF system, and the dependent variables $X_{j}(j=14,15, \cdots, 20)$ represents the outcome products of the BF system.

Table 1 The independent and dependent variables of the BF ironmaking system

\begin{tabular}{|c|c|c|c|}
\hline Independent variables & Input materials & Dependent variables & Outcome products \\
\hline$X_{I}$ & $C_{[\text {Coal] }}$ & $X_{14}$ & $C O_{2[B F}$ gas $]$ \\
\hline$X_{2}$ & $O_{2[\text { Hot air }]}$ & $X_{15}$ & $C O_{[B F \text { gas }]}$ \\
\hline$X_{3}$ & $C_{[}$Coke $]$ & $X_{16}$ & 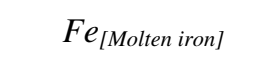 \\
\hline$X_{4}$ & $\mathrm{Fe}_{2} \mathrm{O}_{3[\text { Ferrous }]}$ & $X_{17}$ & $\mathrm{Fe}_{3} \mathrm{C}_{[\text {Molten iron] }}$ \\
\hline$X_{5}$ & $\mathrm{FeO} \mathrm{O}_{[\text {Wustite] }}$ & $X_{18}$ & $M n_{[\text {Slags] }}$ \\
\hline$X_{6}$ & $\mathrm{Fe}_{3} \mathrm{O}_{4[\text { Ferrous }]}$ & $X_{19}$ & Silicate $_{[\text {Slags] }}$ \\
\hline$X_{7}$ & $\mathrm{MnO}_{2[\mathrm{Ore]}}$ & $X_{20}$ & $H_{2[B F \text { gas }]}$ \\
\hline$X_{8}$ & $M n O_{\text {[Wustite] }}$ & & \\
\hline$X_{9}$ & $\mathrm{Mn}_{3} \mathrm{O}_{4[\text { Wustite] }}$ & & \\
\hline$X_{10}$ & $\mathrm{Ca}_{2} \mathrm{CO}_{3[f / u x]}$ & & \\
\hline$X_{11}$ & $\mathrm{CaO}_{[f l u x]}$ & & \\
\hline$X_{12}$ & $\mathrm{Al}_{2} \mathrm{O}_{3[\text { Ore] }}$ & & \\
\hline$X_{13}$ & $\mathrm{H}_{2} \mathrm{O}_{[\text {Hot air }]}$ & & \\
\hline
\end{tabular}

By subtracting the reuse equations from the generation equations, the input variables $X_{i}$ $(i=1,2, \ldots, n, n=13) \quad$ is expressed by the complete S-system dynamic equations relevant to the outcome variables $X_{j}(j=n+1, n+2, \ldots, n+m, m=7)$, as the following Eq. (18).

$$
X_{i}=\alpha_{i} \prod_{j=n+1}^{n+m} X_{j}^{g_{i j}}-\beta_{i} \prod_{j=n+1}^{n+m} X_{j}^{h_{i j}}
$$

in which, $\quad a_{i j}=g_{i j}-h_{i j} ; \quad b_{i}=\ln \left(\beta_{i}\right)-\ln \left(\alpha_{i}\right)=\ln \left(\beta_{i} / \alpha_{i}\right)$;

$g_{i j}, h_{i j}$ - Dynamic progressions; $\alpha_{i}, \beta_{i}$ - Velocity constants.

In the same way, the basic dynamic equations relevant to the independent variables $X_{i}$ can also be written in the following expression, which is decided by the principles of mass balance.

$$
X_{i}=\sum_{j=n+1}^{n+m} \gamma_{j} v_{j i}-\sum_{j=n+1}^{n+m} v_{i j}=V_{i}^{+}-V_{i}^{-}
$$

In which, the concentration of each reactant is represented by the variable $X_{i}$ and $X_{j}$. Each pathway from the input materials $X_{i}$ to the outcome products $X_{j}$ is indicated by $v_{i j}$. The stoichiometric relationship is indicated by the parameter $\gamma_{j}$. All pathways of $X_{i}$ that contribute to the generation reactions are collected and expressed as $V_{i}^{+}$. On the contrary, the sum of all reuse reactions of $X_{i}$ is expressed as $V_{i}^{-}$. Hereby, it is customary to denote the number of independent variables and dependent variables as $n$ and $m$ respectively. Via using Eq. (19), the outcome variables including carbon emissionsat any time of the reactions can be subtracted from the generation rate of the independent variables by the reuse rate of other variables. 


\section{Results and discussions}

The data for this study is reported by a steel plant's No. 1 blast furnace in Jinan Steel Co. The available volume of the blast furnace is $1436 \mathrm{~m}^{3}$, the belly diameter is $9500 \mathrm{~mm}$, the hearth diameter is $8400 \mathrm{~mm}$, and the cross-sectional area of the hearth is $55.5 \mathrm{~m}^{2}$. According to the micro-carbon accounting model proposed above, the independent and dependent variables are listed in Table 2 with the corresponding initial values and the stable values. The initial values depend on the statistic data from the blast furnace No. 1 on June $1^{\text {st }}$ and the stable values is recorded as ending the reaction cycle every 130 minutes approximately.

Table 2 The modeling variables with the initial and stable values

\begin{tabular}{|c|c|c|c|}
\hline Variables & $X_{i}$ & Initial values $/ \mathrm{kg}$ & Stable values $/ \mathrm{kg}$ \\
\hline$C_{[\text {Coall }]}$ & $X_{1}$ & 830.74 & 9.68 \\
\hline$O_{2[\text { Hot air }]}$ & $X_{2}$ & 871.81 & 19.57 \\
\hline$C_{[\text {[Coke] }}$ & $X_{3}$ & 938.27 & 40.53 \\
\hline $\mathrm{Fe}_{2} \mathrm{O}_{3[\text { Ferrous] }}$ & $X_{4}$ & 826.50 & 32.40 \\
\hline $\mathrm{FeO} \mathrm{O}_{[\text {Wustite] }}$ & $X_{5}$ & 468.08 & 16.13 \\
\hline $\mathrm{Fe}_{3} \mathrm{O}_{4[\text { Ferrous] }}$ & $X_{6}$ & 106.70 & 46.95 \\
\hline $\mathrm{MnO}_{2[\mathrm{Ore}]}$ & $X_{7}$ & 384.12 & 4.69 \\
\hline $\mathrm{MnO}_{[}$Wustite] & $X_{8}$ & 175.82 & 2.56 \\
\hline $\mathrm{Mn}_{3} \mathrm{O}_{4[}[$ Wustite] & $X_{9}$ & 5.93 & 1.38 \\
\hline $\mathrm{Ca}_{2} \mathrm{CO}_{3[f(l u x]}$ & $X_{10}$ & 450.29 & 0.04 \\
\hline $\mathrm{CaO}_{[f f l u x]}$ & $X_{11}$ & 766.70 & 0.32 \\
\hline $\mathrm{Al}_{2} \mathrm{O}_{3[\text { Ore] }}$ & $X_{12}$ & 153.99 & 1.70 \\
\hline $\mathrm{H}_{2} \mathrm{O}_{[\text {Hot air }]}$ & $X_{13}$ & 35.85 & 1.52 \\
\hline$C O_{2[B F \text { gas }]}$ & $X_{14}$ & 418.40 & 2081.00 \\
\hline$C O_{[B F \text { gas }]}$ & $X_{15}$ & 2.35 & 2372.12 \\
\hline$F e_{[M o l t e n ~ i r o n]}$ & $X_{16}$ & 508.78 & 1545.10 \\
\hline $\mathrm{Fe}_{3} \mathrm{C}_{[\text {[Molten iron] }}$ & $X_{17}$ & 303.03 & 586.72 \\
\hline
\end{tabular}




\begin{tabular}{lccc}
\hline Variables & $X_{i}$ & Initial values $/ \mathrm{kg}$ & Stable values $/ \mathrm{kg}$ \\
\hline${\text { Mn } n_{[\text {Slags }]}}$ & $X_{18}$ & 1.35 & 2.67 \\
Silicate $[$ Slags] & $X_{19}$ & 344 & 736 \\
$H_{2[B F \text { gas] }}$ & $X_{20}$ & 2.00 & 1.92 \\
\hline
\end{tabular}

Through using the computation program developed by the authors, the initial values in Table 2 is substituted into Eq. (19) of the carbon accounting model for iterations. The carbon emissions of the NO.1 blast furnace are accurately computed. The emission amount of $\mathrm{CO}_{2}\left(X_{14}\right)$ and CO $\left(X_{15}\right)$ in the BF gas are estimated and each value of them in each iteration is demonstrated in Table 3. Comparing with the iteration values in the $10^{\text {th }}$ iteration in Table 3 and the stable values in Table 2, the errors between the estimated value and the real value of $\mathrm{CO}_{2}$ and $\mathrm{CO}$ are respectively $9.28 \%$ and $13.5 \%$, only after 10 iterations.

Table 3 The iteration values of the major carbon emissions in BF

\begin{tabular}{|c|c|c|}
\hline $\begin{array}{ll}\text { Iterations } & \text { Carbon emissions } \\
\end{array}$ & $\mathrm{X}_{14}\left(\mathrm{CO}_{2}\right) / \mathrm{kg}$ & $X_{15}(\mathrm{CO}) / \mathrm{kg}$ \\
\hline 0 & 418.40 & 2.35 \\
\hline 1 & 654.98 & 453.21 \\
\hline 2 & 873.19 & 763.97 \\
\hline 3 & 1075 & 863.57 \\
\hline 4 & 1257.5 & 1035.89 \\
\hline 5 & 1420.6 & 1389.64 \\
\hline 6 & 1563 & 1638.45 \\
\hline 7 & 1683 & 1721.65 \\
\hline 8 & 1777.7 & 1637.31 \\
\hline 9 & 1838.2 & 1867.24 \\
\hline 10 & 1887.8 & 2051.69 \\
\hline
\end{tabular}

With using the iteration program, the outcome products including the carbon emissions on each day is accurately computed and estimated depending on the amount of input materials and fuels. For example, all carbon containing products on June $2^{\text {nd }}$ is computed with respect to the time. The diagram of carbon emissions relevant to the time is illustrated as Fig. 3. 


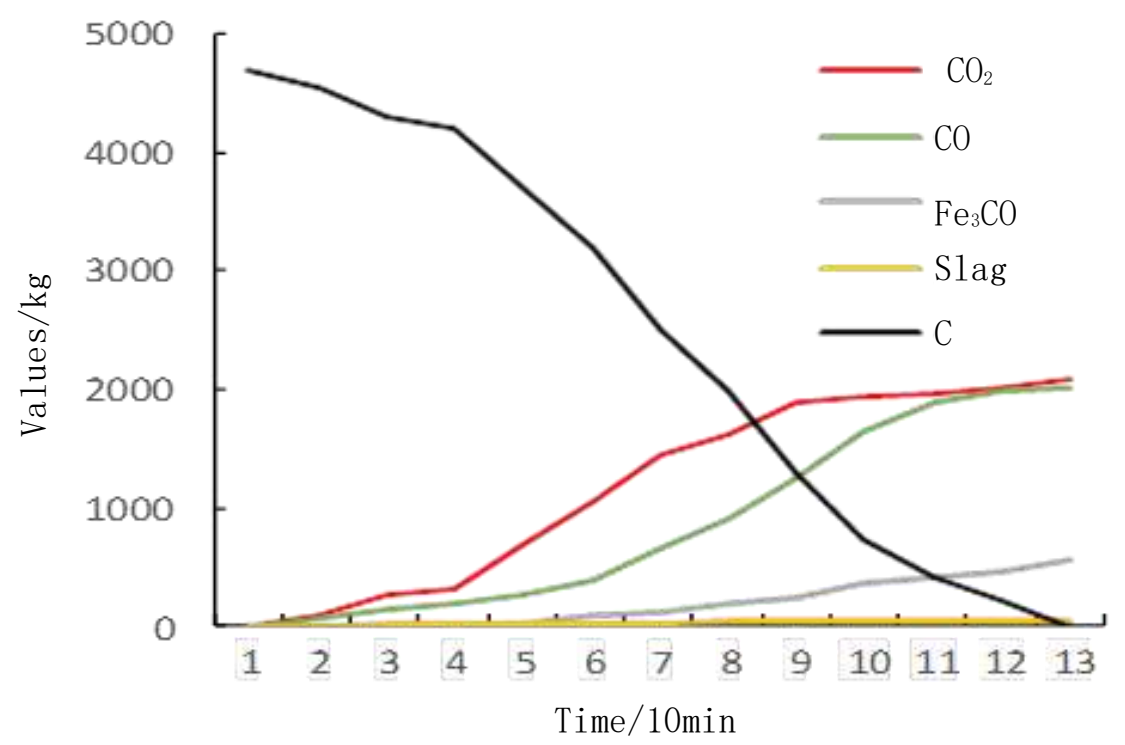

Fig. 3 The diagram of carbon emissions relevant to the time

It can be seen from Fig. 3 that the imported coke and pulverized coal used as fuel are mainly transformed to the $\mathrm{BF}$ gas with the major ingredients of $\mathrm{CO}_{2}$ and $\mathrm{CO}$. A part of the carbon element enters into the molten iron in the form of $\mathrm{Fe}_{3} \mathrm{C}$ through the carburizing reaction occurring in the blast furnace ironmaking process. A few proportion of the carbon element enters into the dusts of $\mathrm{BF}$ gas. In order to verify the accounting values of the carbon emissions, the real values of $\mathrm{CO}_{2}$ and $\mathrm{CO}$ in the $\mathrm{BF}$ gas collected from June 1 to 10 are compared with the simulation results by using the micro-carbon accounting model. The comparison is demonstrated in Table 4 and the accounting errors of the estimations on the carbon emissions are tolerable with the mean errors of $5.23 \%$ and $6.77 \%$ respectively.

Table 4 The comparison between the simulated values and the real values (Unit: $\mathrm{kg}$ )

\begin{tabular}{|c|c|c|c|c|c|c|}
\hline date Indicator & $\begin{array}{l}\text { Simulated } \\
\text { value of } \\
\mathrm{CO}_{2} \\
\end{array}$ & $\begin{array}{l}\text { Real value } \\
\text { of } \mathrm{CO}_{2}\end{array}$ & $\begin{array}{l}\text { Accounting } \\
\text { error }\end{array}$ & $\begin{array}{l}\text { Simulated } \\
\text { value of } \\
\text { CO }\end{array}$ & $\begin{array}{l}\text { Real value } \\
\text { of CO }\end{array}$ & $\begin{array}{l}\text { Accounting } \\
\text { error }\end{array}$ \\
\hline $06-01$ & 2095.60 & 2054.44 & $2.0 \%$ & 2013.65 & 2173.25 & $7.3 \%$ \\
\hline $06-02$ & 2089.34 & 2012.32 & $3.8 \%$ & 2007.64 & 2314.47 & $13.3 \%$ \\
\hline $06-03$ & 2191.40 & 2275.94 & $3.7 \%$ & 2105.70 & 2124.75 & $0.9 \%$ \\
\hline 06-04 & 2183.67 & 2182.2 & $0.1 \%$ & 2098.27 & 2286.28 & $8.2 \%$ \\
\hline $06-05$ & 2270.33 & 2295.43 & $1.1 \%$ & 2181.54 & 2246.44 & $2.9 \%$ \\
\hline $06-06$ & 2359.85 & 1998.18 & $18.1 \%$ & 2267.56 & 2131.29 & $6.4 \%$ \\
\hline $06-07$ & 2421.87 & 2385.65 & $1.5 \%$ & 2327.16 & 2446.02 & $4.9 \%$ \\
\hline 06-08 & 2462.03 & 2596.44 & $5.2 \%$ & 2365.75 & 2066.4 & $14.5 \%$ \\
\hline 06-09 & 2358.47 & 2559.32 & $7.8 \%$ & 2266.24 & 2221.93 & $2 \%$ \\
\hline $06-10$ & 2095.60 & 1922.22 & $9 \%$ & 2013.65 & 2173.25 & $7.3 \%$ \\
\hline \multicolumn{2}{|c|}{ The degree of freedom } & \multicolumn{2}{|c|}{ The F value } & \multicolumn{3}{|c|}{ The $\mathrm{P}$ value of the model } \\
\hline \multicolumn{2}{|c|}{1} & \multicolumn{2}{|r|}{10.42} & & \multicolumn{2}{|c|}{0.012} \\
\hline
\end{tabular}


Regarding the real value of $\mathrm{CO}_{2}$ emission as the response value and regarding the simulated value as the dependent variable, a regression curve fitting and residual analysis is conducted with a confidence degree of $95 \%$. The results of the accuracy analysis on the carbon accounting model are demonstrated in Fig. 4.

Depending on the analysis of variances and residuals, a regression fitting model is established with the degree of freedom 1 to verify the computing accuracy of the micro-carbon accounting model. Correspondingly, the F value is 10.42 and the $\mathrm{P}$ value is 0.012 . When the $\mathrm{P}$ value is less than 0.05 , the regression analysis verifies that micro-carbon accounting model is reliable in the confidence interval. It can be seen from Fig. 4 (a) that the scatter points in the diagram of normal distribution probability are basically distributed on both sides of the fitting line. Fig. 4 (b) shows that most residuals of the carbon emissions are distributed around the contour line 0 except the residual value on the $6^{\text {th }}$ day is greater biased. Fig. 4 (c) and (d) demonstrates the frequency of the residuals of carbon emissions from June $1^{\text {st }}$ to $10^{\text {th }}$. All these figures indicate that the errors between the real values and the simulated values of the carbon emissions are tolerable and the simulation accuracy of the micro-carbon accounting model is acceptable.

(a)The normal distribution probability of the residual(b)The residual to the fitted value of carbon emission
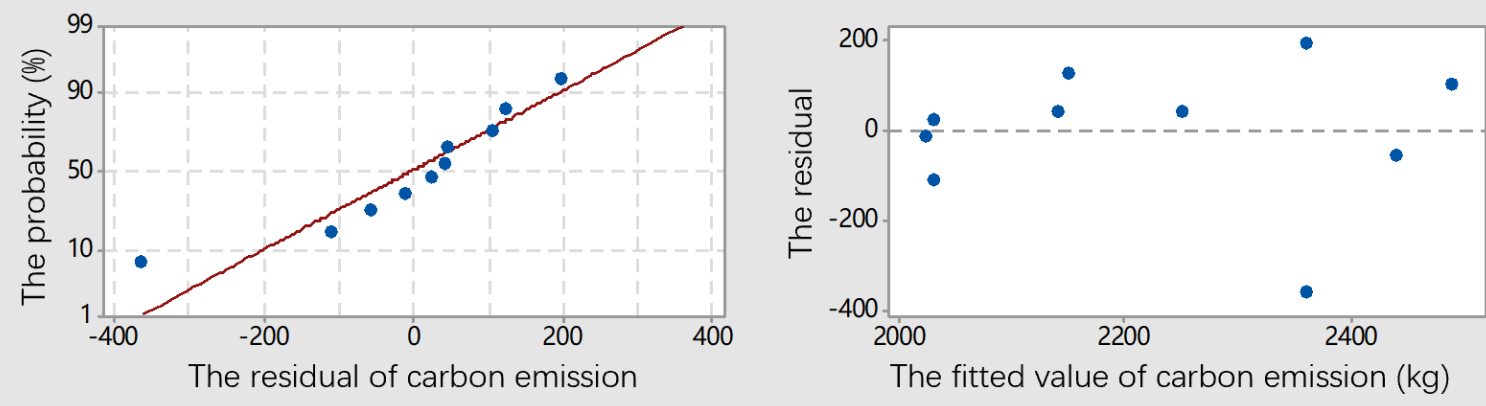

(c) The frequency histogram of the residual

(d)The residual to the carbon emission cycle
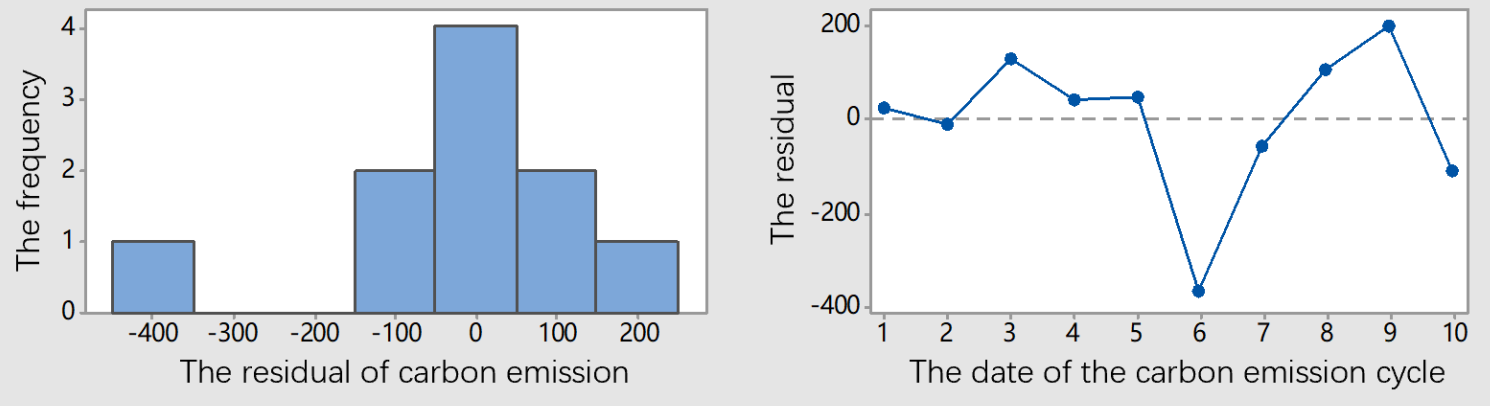

Fig. 4 The residual analysis on the carbon accounting model

\section{Conclusions and Policy Implications}

The micro-carbon accounting model based on the micro-level process can be established on a dynamic S-system with using the approximation method of power law and Michaelis-Menten law. 
All reactant variables at the operating nodes are included in the expression formulas of power law so that massive complex relations between reactants and products can be linearized in the logarithmic space. Relatively simpler linear approximation can compute the reaction velocity and the concentration of products more accurately. Actually, the carbon accounting simulation on the $\mathrm{BF}$ ironmaking process demonstrates that the mean errors of the $\mathrm{CO}_{2}$ and $\mathrm{CO}$ emissions are respectively $5.23 \%$ and $6.77 \%$. It shows that micro-carbon accounting model is adequate and effective for accurately estimating the concentration, mass, and their change velocity of carbon emissions. This method better addresses the challenge of severely overestimation on carbon emissions in the carbon accounting of the ironmaking industry.

Via using the micro-carbon accounting model, all outcome products including the carbon emissions in every time interval can be accurately computed depending on the amount of input materials and fuels. The quantitative details of the reactants and products can be analyzed by simulating the process of carbon emissions. This micro-carbon accounting model facilitates the discovery of the principles of the carbon emissions so that more accurate carbon accounting methodology can be proposed for the leaner management. It offers a possibility of substituting the IPCC's universal method with the micro-carbon accounting model in a micro-level carbon accounting for a given industrial system.

Further study on the carbon accounting based on the micro-level process principles provides a new approach to improving the quantitative and controllable carbon scheduling, optimizing the allocation of production resources, and making policies for the lean and value-added management of carbon assets. It is of great significance for steel industries to endogenously drive the low-carbon transformation, improve the top-level mechanism of the carbon market, and accelerate the unification of the national carbon market.

\section{Declarations:}

Competing interests:

Not applicable

Availability of data and materials:

Some or all data, models, or code generated or used during the study are available from the corresponding author by request.

\section{Funding:}

The research reported in this paper is supported by Research Fund of National Natural Science Foundation of P. R. China (NO. 51775392). 
Authors\& apos; contributions:

Shujun Yu: Design the article and complete the experiment

Fangjia Lin: Participate in and complete experiments

Gang Zhao: Some constructive suggestions are put forward

Zequan Zhang: Organize and collect data

Hua Zhang: Analyze data and review articles

Acknowledgement:

The research reported in this paper is supported by Research Fund of National Natural Science Foundation of P. R. China (NO. 51775392). Sincere thanks to all reviewers and editors for their comments and suggestions.

Authors\&apos; information :

Shujun Yu, Prof., Ph.D.

Evergande School of Management, Wuhan University of Science and Technology, Wuhan, Hubei 430081, China

yushujun@,wust.edu.cn

Gang Zhao, Prof., Ph.D.

Hubei Key Laboratory of Mechanical Transmission and Manufacturing Engineering, Wuhan University of Science and Technology, Wuhan, Hubei 430081, China

jasonzhao@wust.edu.cn

\section{References}

AnaMaria Iosif, Francois Hanrot, Denis Ablitzer. Process integrated modelling for steelmaking Lif e Cycle Inventory analysis Original Research Article [J]. Environmental Impact Assessment Review, October 2008; 28 (7): 429-438.

Butner K., Geude D., Hittner J. Mastering carbon management: balancing trade - offs to optimize supply chain efficiencies [J]. IBM Institute for Business Value, 2008.

C. Rynikiewicz. The climate change challenge and transitions for radical changes in the European steel industry [J]. Journal of Cleaner Production, 2008; 16: 781-789.

Gang Zhao, Hua Zhang, Guangjun Zhang, Liming Guo. Morphology and coupling of environmental boundaries in an iron and steel industrial system for modelling metabolic behaviours of mass and energy. Journal of Cleaner Production, 2015; 100 (8): 247-261.

Gang Zhao, Xiang Zhang, Cheng Fang, Dan Ruan, Yanan Wang. Systemic boundaries in industrial systems: A new concept defined to improve LCA for metallurgical and manufacturing systems. 
Journal of Cleaner Production, 2018; 187: 717-729.

Gang Zhao, Xing Gao, Shaoyuan Yang, JiahuDuan, Jiaqiang Hu, Xiaokang Guo, Zhongren Wang. A mechanism model for accurately estimating carbon emissions on a micro scale of the steel industrial system. ISIJ International. 2019; 59 (2): 381-390.

Han Liyan, Huang Gubo. Attributes and pricing of technology's carbon asset [J]. Statistical Research, 2015; 32(2): 10-15.

J. Davis, R. Geyer, J. Ley, et al. Time-dependent material flow analysis of iron and steel in the UK [J]. Resources, Conservation and Recycling, 2007; 51: 118-140.

Jan Peter Andersen, Barry Hyman. Energy and material flow models for the US steel industry [J]. Energy, 2001; 26: 137-159.

Karen R. Polenske, Francis C. McMichael. A Chinese cokemaking process-flow model for energy and environmental analyses [J]. Energy Policy, August 2002; 30 (10): 865-883.

LU Zhongwu, CAI Jiuju. Fundamentals of systemic energy conservation [M]. Shenyang: Northeastern University Press, 2010; 8: 15-16.

LU Zhongwu, CAI Jiuju, YU Qingbo, et al. Study on the metod for calculating influence of mass flow on energy consumption in steel manufacturing process [J]. Acta Metallurgica Sinica, 2000; 36 (4): $370-378$.

MA Qiuzhuo, SONG Haiqing, CHEN Gong-yu. A Study on Low-carbon Product Pricing and Carbon Emission Problems under the Cap-and-Trade System [J]. Journal of Industrial Engineering and Engineering Management, 2014; 28 (2): 127-136.

Marland G, Fruitk, Sedjor. Accounting for sequestered carbon: the question of permanence [J]. Environmental Science \& Policy, 2001; 4 (6): 259-268.

Mohan Yellishetty, Gavin M. Mudd, P. G. Ranjith. The steel industry, abiotic resource depletion and life cycle assessment: A real or perceived issue [J]. Journal of Cleaner Production, 2011; 19: $78-90$.

Mohan Yellishetty, Gavin M. Mudd, P. G. Ranjith, A. Tharumarajah. Environmental life-cycle comparisons of steel production and recycling: Sustainability issues, problems and prospects [J]. Environmental Science \& Policy, 2011; 14: 650-663.

National Development and Reform Commission of P. R. China. Notice on the key tasks of starting the national carbon emission trading market. [EB/OL]. (2016-01-11) [2016-09-26]. http://qhs.ndrc.gov.cn/ zcfg/201601/t20160122_772148.html.

Nestor V. Torres. Pathway analysis and optimization in metabolic engineering [M]. Beijing: Chemical Industry Press. 2010: 86.

Pany, Birdsey R A, Fang J, et al. A large and persistent carbon sink in the world's forests [J]. Science, 2011; 333 (6045): 988-993. 
T. Spengler, J. Geldermann, S. Htihre, A. Sieverdingbeck, O. Rentz. Development of a multiple criteria based decision support system for environmental assessment of recycling measures in the iron and steel making industry [J]. Journal of Cleaner Production, 1998; 6 (1): 37-52.

WANG Sufeng, YANG Shanlin, PENG Zhanglin. Research on the power producer's carbon abatement investment in view of multiple uncertainties [J]. Journal of Management Sciences in China, 2016; (2): 41-57.

Wang Wenju, Chen Zhenling. Study on the allocation plan of initial carbon allowances in China's province-level regions: based on the perspective of responsibility and goals, fairness and efficiency [J]. Management World, 2019; (3): 81-98.

Wang Wenjun, Xie Pengcheng, Hu Jilian, et al. Analysis of the relative mitigation cost advantages of carbon tax and ETS for the cement industry [J]. Advances in Climate Change, 2016; (1): $53-60$.

Wang Yanglei, Du Li. Effectiveness of China's carbon finance trading market - Fractal theory analysis based on Beijing carbon trading market [J]. Management World, 2015; (12): 174-175.

YI Lan, LI Zhaopeng, WANG Xiaochuan. Research on the carbon management pattern of Chinese enterprises - based on the establishment of the national carbon market [J]. Science and Technology Management Research, 2016; (11): 247-253.

Zhang Haiou, Huang Cheng, Wang Guilan, Li RunSheng, Zhao Gang. Comparison of energy consumption between hybrid deposition \& micro-rolling and conventional approach for wrought parts. Journal of Cleaner Production, August 2020; 279 (10):1-11.

ZHANG Junrong, WANG Zidan, TANG Ling, et al. The simulation of carbon emission trading system in Beijing-Tianjin-Hebei region: An analysis based on system dynamics [J]. Chinese Journal of Management Science, 2016; 24 (3): 1-8.

ZHAO Liming, YIN Jianli. Bi-level programming model of carbon emission reduction decisionmaking under the coexistence of carbon trading and carbon tax [J]. Journal of Management Science, 2016; (1): 137-146.

Zhang Yalian, Zhang Su. Consideration on the construction of enterprise carbon asset management system [J]. Environmental Protection, 2013; (8): 46-47. 


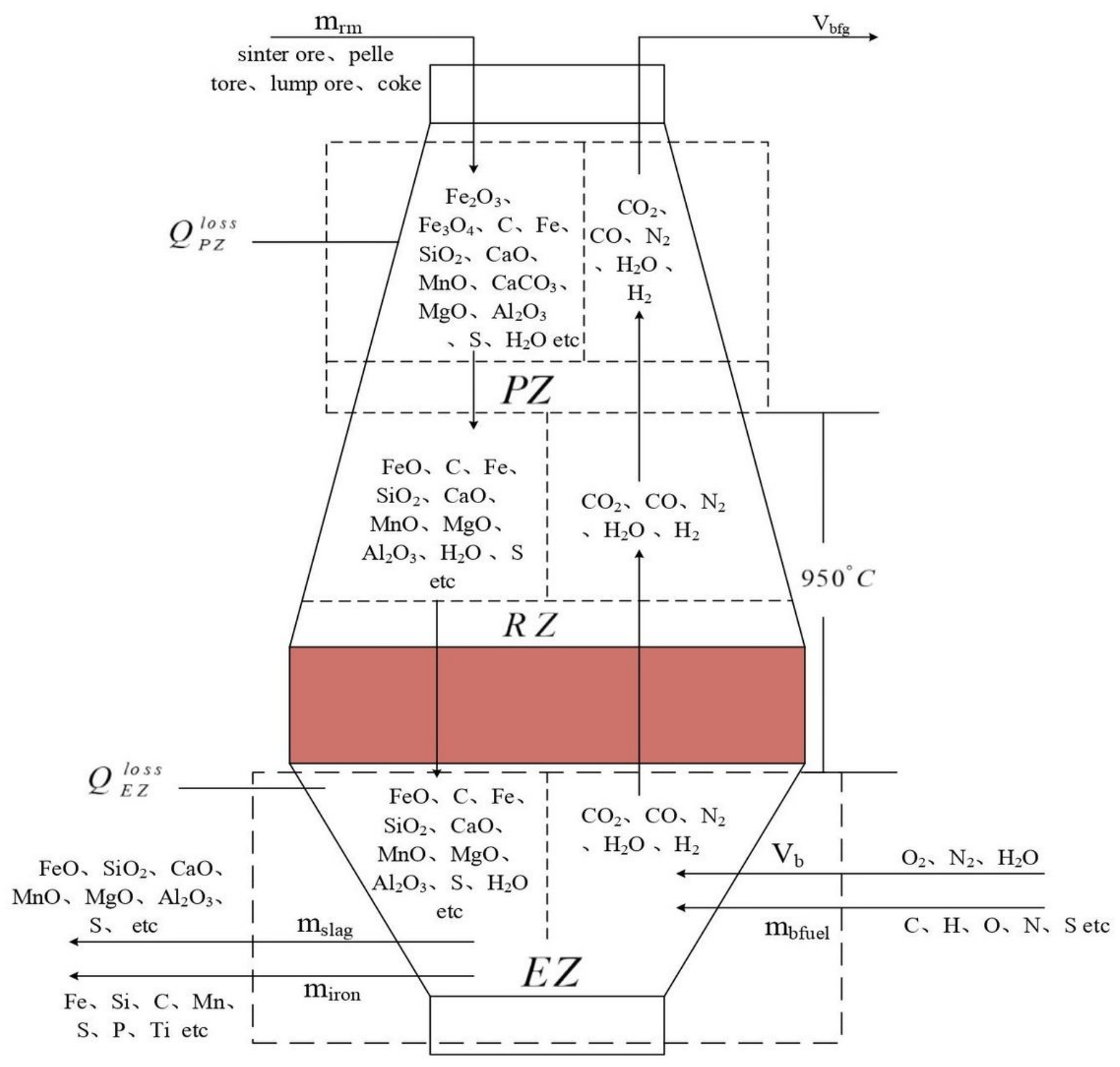

Figure 1

The substance flows inside the blast furnace 


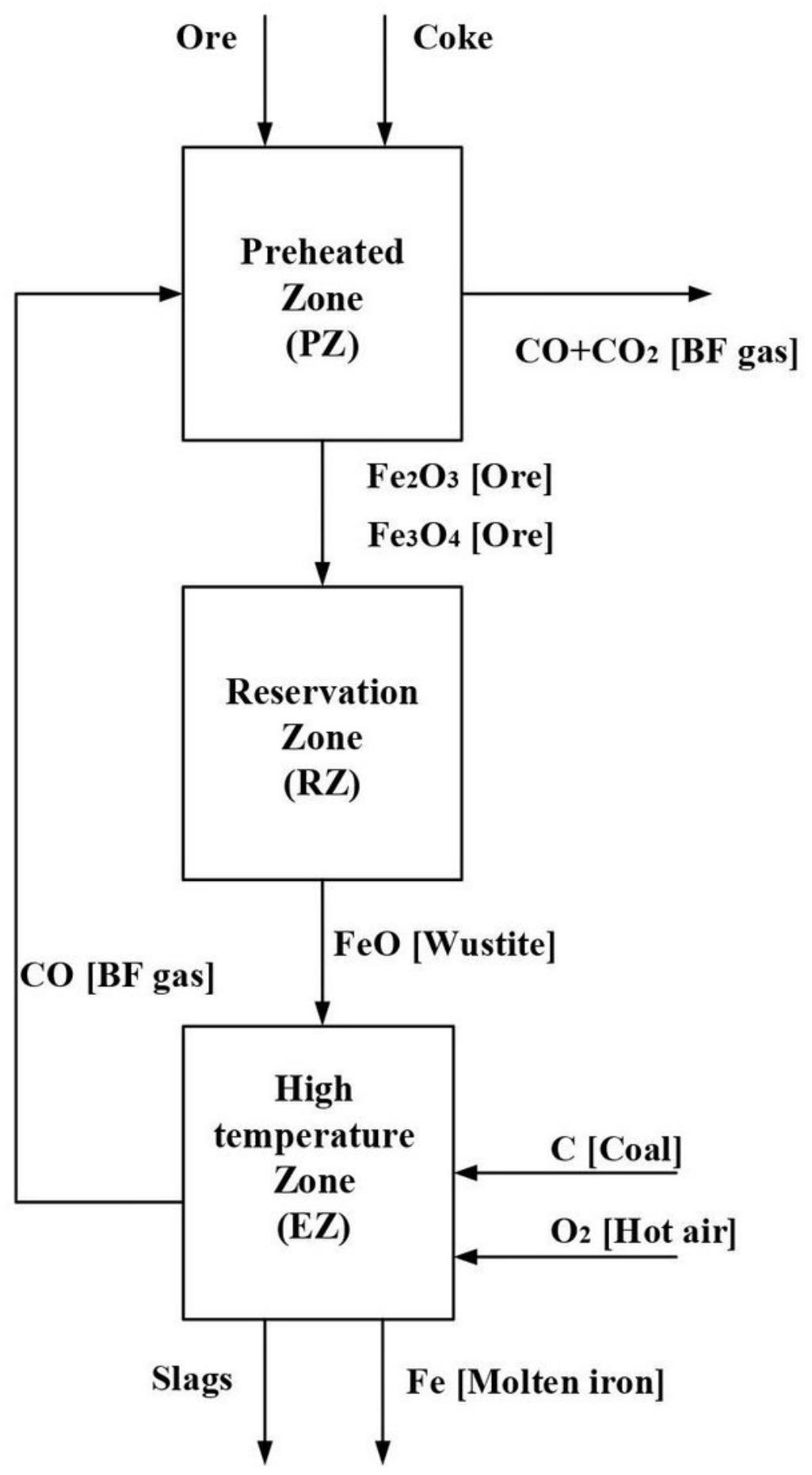

Figure 2

The systemic dynamic model of the blast furnace ironmaking system 


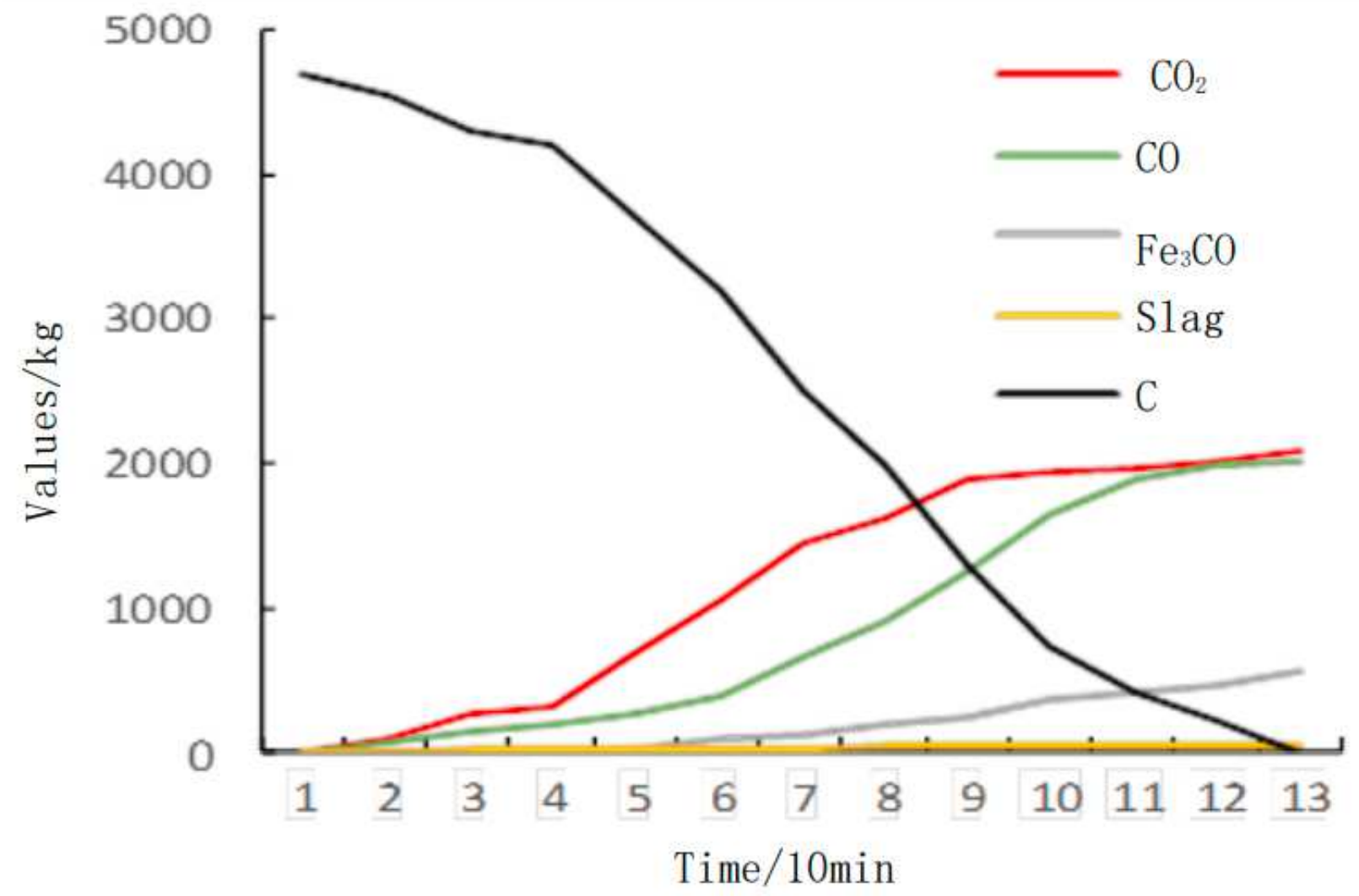

Figure 3

The diagram of carbon emissions relevant to the time 
(a)The normal distribution probability of the residual(b)The residual to the fitted value of carbon emission
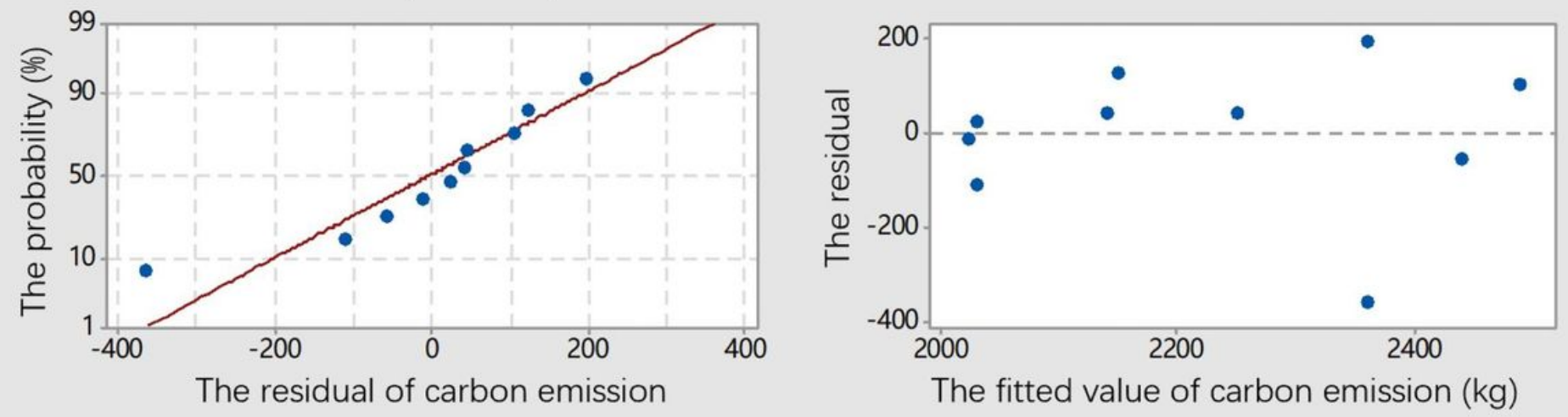

(c) The frequency histogram of the residual
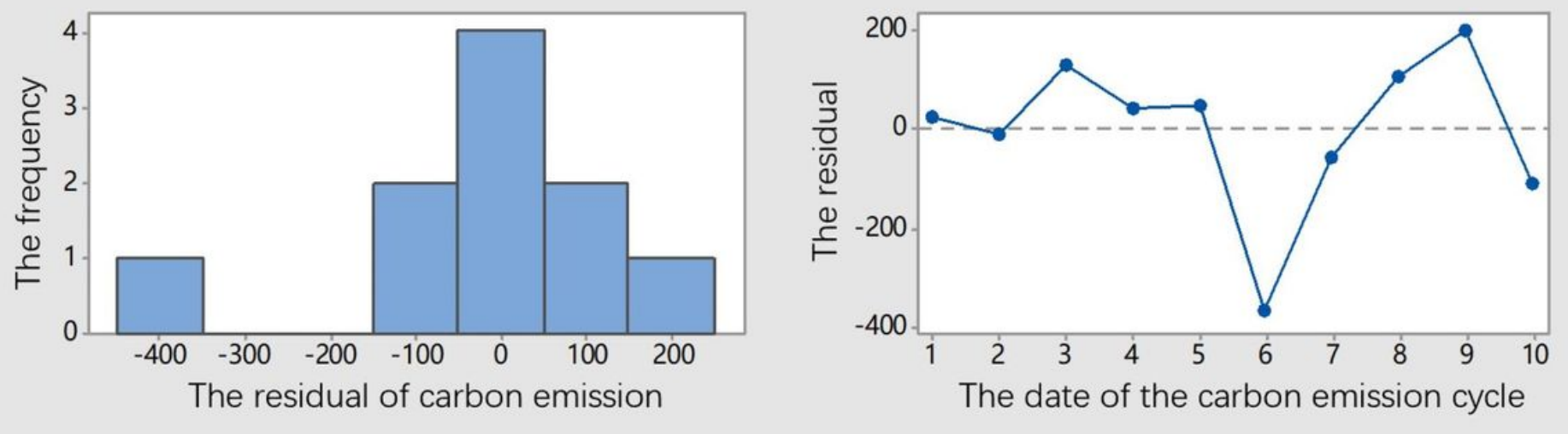

\section{Figure 4}

The residual analysis on the carbon accounting model 